\title{
Article
}

\section{An Efficient Method for the Genetic Transformation of Acmella oleracea L. (Spilanthes acmella Linn.) with Agrobacterium tumefaciens}

\author{
Valentina Maggini ${ }^{1,2, *(\mathbb{C})}$, Priscilla Bettini ${ }^{2}$, Fabio Firenzuoli ${ }^{1,+}+\left(\mathbb{C}\right.$ and Patrizia Bogani ${ }^{2,+}$ (i) \\ 1 Research and Innovation Center in Phytotherapy and Integrated Medicine (CERFIT), \\ Careggi University Hospital, Via delle Oblate 4, 50141 Florence, Italy; fabio.firenzuoli@unifi.it \\ 2 Department of Biology, University of Florence, Via Madonna del Piano 6, Sesto Fiorentino, \\ 50019 Florence, Italy; priscilla.bettini@unifi.it (P.B.); patrizia.bogani@unifi.it (P.B.) \\ * Correspondence: valentina.maggini@unifi.it \\ + Co-last author.
}

check for

updates

Citation: Maggini, V.; Bettini, P.; Firenzuoli, F.; Bogani, P. An Efficient Method for the Genetic Transformation of Acmella oleracea L. (Spilanthes acmella Linn.) with Agrobacterium tumefaciens. Plants 2021, 10, 198. https://doi.org/ $10.3390 /$ plants10020198

Received: 28 December 2020

Accepted: 19 January 2021

Published: 21 January 2021

Publisher's Note: MDPI stays neutral with regard to jurisdictional claims in published maps and institutional affiliations.

Copyright: (c) 2021 by the authors. Licensee MDPI, Basel, Switzerland. This article is an open access article distributed under the terms and conditions of the Creative Commons Attribution (CC BY) license (https:// creativecommons.org/licenses/by/ $4.0 /)$.

\begin{abstract}
Acmella oleracea L. is an important medicinal plant, commonly known as the toothache plant. It is a rich source of secondary metabolites used for the treatment of different human disorders. The demand for Acmella oleracea L. has increased due to its putative health benefits (in terms of both biomass quantity and bioactive compound purification). In vitro plant cultures have allowed the rapid increase of raw material availability through the use of suitable regeneration and multiplication systems. On the other hand, there is a general lack of methods for Acmella genetic transformation as a promising new technological approach for the improvement of secondary metabolites. In this work, an efficient transformation protocol has been established using the Agrobacterium tumefaciens LBA4404 strain bearing the binary vector pBI121 containing the NPTII gene for the resistance to kanamycin. Plant genetic transformation has been verified by direct polymerase chain reaction and GUS assay on regenerants. Transformation efficiency has been affected by the high level of the selection agent kanamycin. To our knowledge, this is the first report on the genetic transformation of $A$. oleracea, paving the way to further studies to improve in vitro plant growth and secondary metabolite production.
\end{abstract}

Keywords: Acmella oleracea; Agrobacterium; genetic transformation; stem node regeneration; kanamycin resistance; GUS detection

\section{Introduction}

Acmella oleracea (L.) R.K. Jansen [1], also known as Spilanthes acmella Murr. [2-4] or Spilanthes oleracea L. [5], is part of the Asteraceae family. It was first discovered in Peru and is now commonly found in tropical and subtropical regions across the world, especially in the north of Brazil, where it is known as jambu [6-9]. Generally, this plant is an annual or perennial herb of short duration and reaches a height ranging from 20 to $90 \mathrm{~cm}$. The leaves are of simple origin, oval, with irregular edges. The stem is cylindrical and moderately plastic. The typical flower color is generally yellow, with a red tip, and dome-shaped, with well-arranged sepals surrounded by small petals [10]. It is an important medicinal plant, traditionally used for its analgesic and anti-inflammatory properties (mainly for toothache and oral cavity inflammation treatments), but also for its recognized antipyretic, anticonvulsant, antidiarrheal, antidiuretic, antiseptic, anti-fungal, anti-protozoal, and insecticidal properties. Moreover, it is used for culinary purposes $[7,8,10,11]$. These properties are a result of its endogenous content, of bioactive compounds, such as sterols, coumarins, flavonoids, saponins, terpenoids, polysaccharides, and, in particular, alkylamides [7,8,12]. Among the alkylamides, spilanthol ((E, E, Z)-2,6,8-decatrienoic acid N-isobutylamide) is considered to be the most potent bioactive compound found in A. oleracea. First identified 
by Gerber in 1903 as identical to affinin 1, spilanthol has been mostly found in Acmella flowers, leaves, and stems $[4,7,8,12-16]$, but also in roots $[17,18]$, and its accumulation in in vitro cell cultures has been documented [2,3]. Due to its pharmacological importance, based on a series of effects typical of alkylamides, such as analgesic, neuroprotective, antioxidant, antimutagenic, anti-cancer, anti-inflammatory, antimicrobial, anti-larvicidal, and insecticidal activities [19], many protocols for spilanthol production and extraction have been developed (see [19] for a review; [20]). Besides recent in vivo treatments with biostimulants [21], a good approach to obtain a great number of plants, in a short period of time under selected standardized conditions of cultivation, is the use of in vitro plant cultures [2,3,8,22-27]. These strategies have allowed rapid improvement of raw material and metabolite production. On the other hand, although their importance in many medicinal species is well known, methods for Acmella genetic transformation are lacking. Hairy roots, for example, have proven to be a promising tool for the increased production of secondary metabolites in hundreds of traditional herbs [28-30]. Moreover, recent developments in metabolic engineering techniques have made possible the introduction of novel biosynthetic pathways in both medicinal and commercial crops to enhance their market and nutritional value [31,32]. Agrobacterium tumefaciens is so far the most used and powerful tool for the introduction of a series of candidate genes and transcriptional regulators in medicinal plants [33,34]. Therefore, since, to our knowledge, there is no data in the literature on the genetic transformation of Acmella spp., in this study, we report the development of the first successful Agrobacterium-mediated transformation protocol for the integration and expression of NPTII and GUS genes.

\section{Results and Discussion}

\subsection{Explant Effect on the Regeneration by Organogenesis in A. oleracea}

Due to increasing market demand, efficient regeneration systems have been reported in A. oleracea. Different established protocols showed that the best hormone combination to induce shoots formation on in vitro and in vivo explants was based on the ratio between 6-Benzylaminopurine (BAP) and 1-Naphthaleneacetic acid (NAA) at different concentrations. Moreover, leaf explants regenerated multiple shoots from in vitro seedlings, and shoot differentiation was better from in vivo nodes than other tissue explants [2,3,23,35-38]. In our work, we used Linsmaier \& Skoog (LS) medium supplemented with $1 \mathrm{mg} / \mathrm{L}$ BAP and $0.1 \mathrm{mg} / \mathrm{L}$ NAA (LS1) to induce shoot proliferation on leaf and nodal explants derived from in vitro 2-month-old Acmella axenic plants. Callus and shoot differentiation was observed on $100 \%$ of nodal stem explants $(n=60)$, starting from the fourth day of culture on LS1 regeneration medium (Figure 1A). After 30 days of cultivation, the average number of $0.5 \mathrm{~cm}$ high shoots per explant was equal to three. Leaf explants (and vice versa) were capable of only proliferating callus. All of the leaf explants showed callus dedifferentiation after 30 days of culture (Figure 1B), and they never produced any seedlings, even after two further transfers on fresh LS1 medium at intervals of 30 days each.
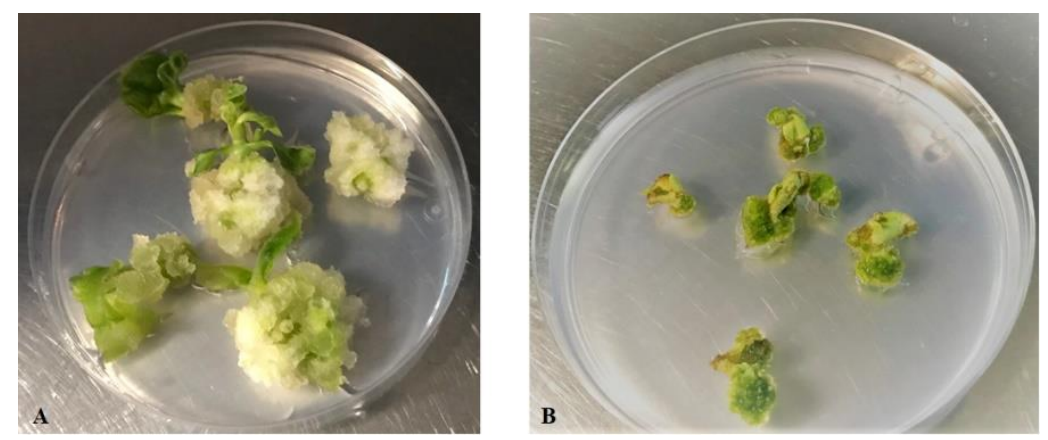

Figure 1. Morphogenetic behavior of A. oleracea nodal (A) and leaf (B) explants after 30 days of culture on LS medium supplemented with $1 \mathrm{mg} / \mathrm{L}$ 6-Benzylaminopurine (BAP) and $0.1 \mathrm{mg} / \mathrm{L}$ 1-Naphthaleneacetic acid (NAA) (LS1 regeneration medium). 
Thus, nodal stems were chosen as sources of explants for transformation of A. oleracea with the A.tumefaciens pBI121 vector, containing the neomycin phosphotransferase NPTII gene for resistance to kanamycin, the selection agent more frequently used in Agrobacteriummediated plant transformation experiments.

\subsection{Agrobacterium-Mediated Transformation}

2.2.1. Determination of a Kanamycin Dose-Response Curve for the Selection of Acmella pBI121 Transformants

In order to evaluate the effect of kanamycin on shoot differentiation, a dose-response curve was planned. Results of the experiments (Figure 2) showed a dose-dependent toxic effect of kanamycin on callus and shoot formation, significantly inhibited from 10 to $25 \mathrm{mg} / \mathrm{L}$ (extremely toxic dose), and completely suppressed at $50 \mathrm{mg} / \mathrm{L}$. An antibiotic concentration of $10 \mathrm{mg} / \mathrm{L}$ was therefore chosen for A. oleracea transformation.

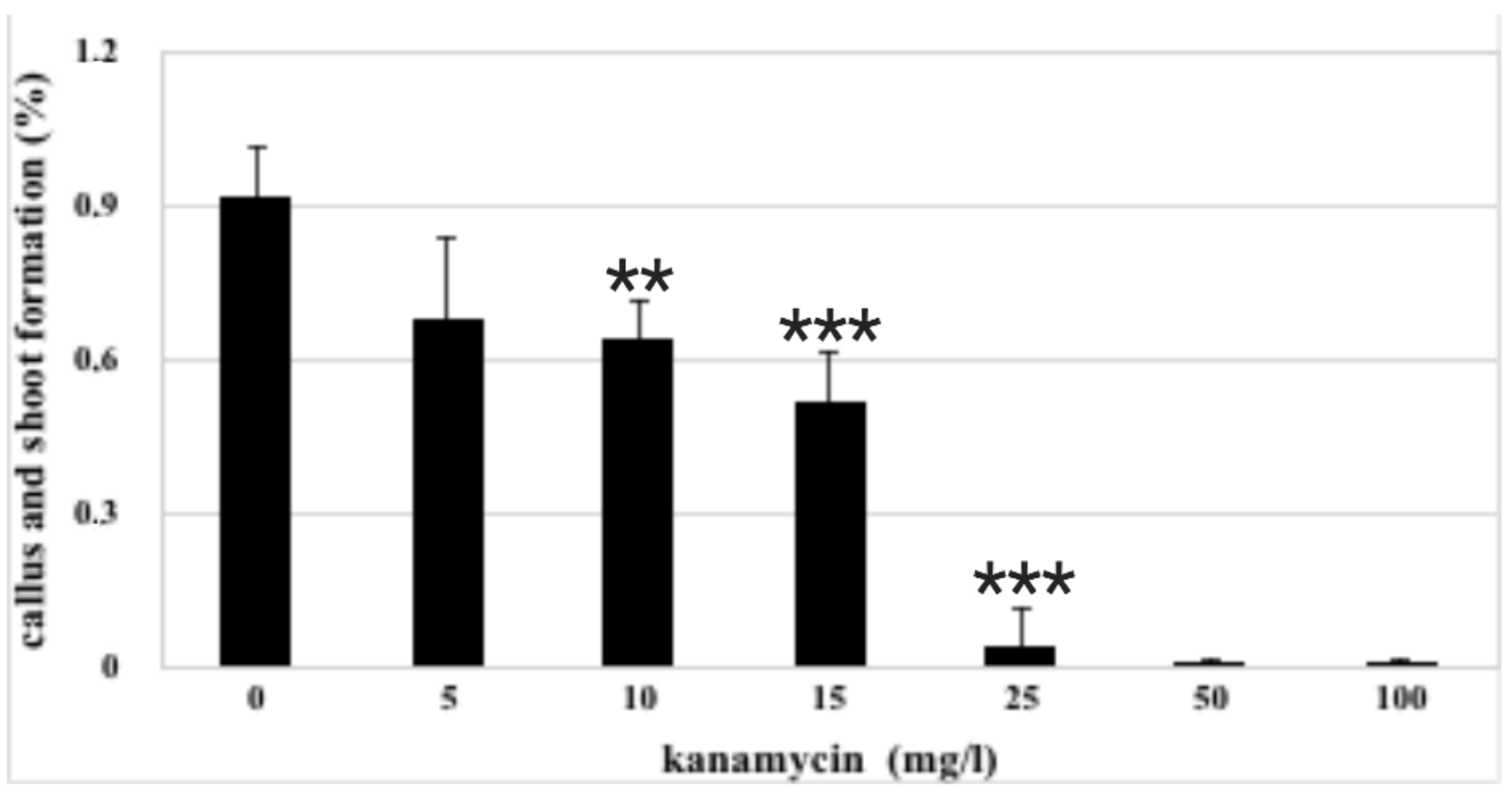

Figure 2. Inhibitory effect of kanamycin on callus and shoot formation from A. oleracea nodal explants after 30 days of culture on LS1 regeneration medium. $n=5$; error bars represent standard deviations referred to five replicates; ${ }^{* *} p \geq 0.01$; *** $p \geq 0.0001$.

\subsubsection{Nodal Explant Infection}

Thirty nodal stem explants were infected with A. tumefaciens LBA4404 strain harboring the pBI121 vector and 30 were used as not infected controls. After $96 \mathrm{~h}$ of co-cultivation, all of the infected explants and half of the non-infected ones were transferred to LS1 selection medium with kanamycin $(10 \mathrm{mg} / \mathrm{L}$, initial selection dose) and cefotaxime $(500 \mathrm{mg} / \mathrm{L})$. Fifteen control explants were placed on plates containing LS1 medium without antibiotics. After 30 days, $92 \%$ of the infected explants, and $25 \%$ of controls, showed callus and shoot regeneration (Figure $3 \mathrm{a}-\mathrm{c}$ ). The presence of shoots on control explants indicated the occurrence of escape from selection at the chosen kanamycin concentration. However, under further selection, the same control regenerated shoots appeared bleached, less vigorous, and stopped their growth after only one transfer on medium with the selection agent. After 40 days from co-cultivation, 23 independent putative transgenics shoots, about $0.5 \mathrm{~cm}$ in length, were isolated and transferred to Wavin containers (Lab Associates B.V., The Netherlands) with half strength LS selection medium containing $2 \%$ sucrose and 
devoid of hormones, to allow root formation and shoot elongation (Figure 3d,e). Only 7 out of 23 shoots survived the selection, and after two months from their isolation showed a reduced growth (Figure 3g) compared to the controls (Figure 3f).
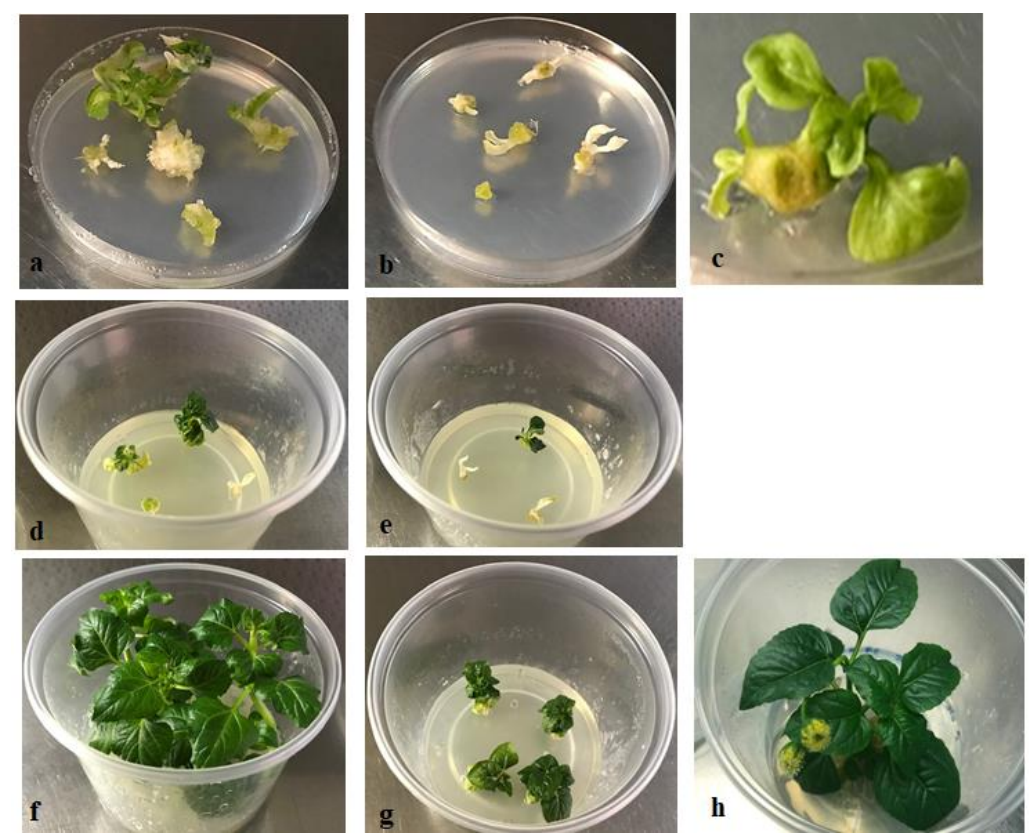

Figure 3. Plant transformation in Acmella oleracea. (a,b) Nodal explants infected with Agrobacterium LBA4404::pBI121 showing regenerated shoots after 30 days of culture on LS1 medium with the addition of $10 \mathrm{mg} / \mathrm{L}$ kanamycin and $500 \mathrm{mg} / \mathrm{L}$ cefotaxime. (c) Control (not infected) nodal explants on the same selection medium 30 days after co-cultivation with Agrobacterium. (d,e) Isolated putative transgenic shoots 40 days after co-cultivation with Agrobacterium on LS1 selection medium. (f) Acmella plantlets isolated from control nodal explants after two months of growth on LS medium devoid of hormones; Acmella transgenic shoots after two (g) and four months (h) of growth on LS selection medium containing $10 \mathrm{mg} / \mathrm{L}$ kanamycin.

\subsection{Molecular Analysis of Putative Transformants}

\subsubsection{Analysis of the Presence of Transgenes by Direct PCR}

Before the molecular analysis of each putative transformant, a sterility test was performed to exclude the presence of Agrobacterium inside the leaf plant tissues used as templates in experiments of direct PCR. Results, reported in Figure S1, clearly showed the absence of Agrobacterium growth in yeast extract-peptone (YEP) medium (supplemented with rifampicin and kanamycin, antibiotics specific for Agrobacterium and its vector, respectively) containing leaf macerates from both putative transformed and untransformed control shoots, as evidenced by the lack of turbidity of the solutions. This method has proven very useful at checking the persistence of Agrobacterium in tobacco transgenic plants [39]. However, it is well-established in literature that cefotaxime concentration of $500 \mathrm{mg} / \mathrm{L}$ (used in our work) completely eliminates the Agrobacterium presence after two weeks from the infection of explants (see for instance [40-42]). Thus, we performed the test on eleven-week-old plants after the isolation from the infected explants, grown on selection medium containing kanamycin and cefotaxime. An alternative time-saving potentiality to test the absence of Agrobacterium could be the PCR amplification with specific primers for marker genes present on Ti helper plasmid (for instance, vir genes) or on Agrobacterium chromosome (e.g., chv genes).

Subsequently, to demonstrate the presence of transgenes in putative A. oleracea transformants, a direct PCR was performed by using a pair of primers amplifying a region of the GUS gene (Table S1). Moreover, a pair of universal primers specific of a chloroplastic region 297 bp long was used as internal control of the direct PCR reaction. Both the reactions 
were performed at $62{ }^{\circ} \mathrm{C}$, the recommended annealing temperature. Results shown in Figure 4 evidenced the presence of the GUS gene only in three regenerated shoots and in the plasmid DNA used as positive control (Figure 4a), while the chloroplastic band was present in all of the samples, suggesting optimal PCR conditions (Figure 4b).
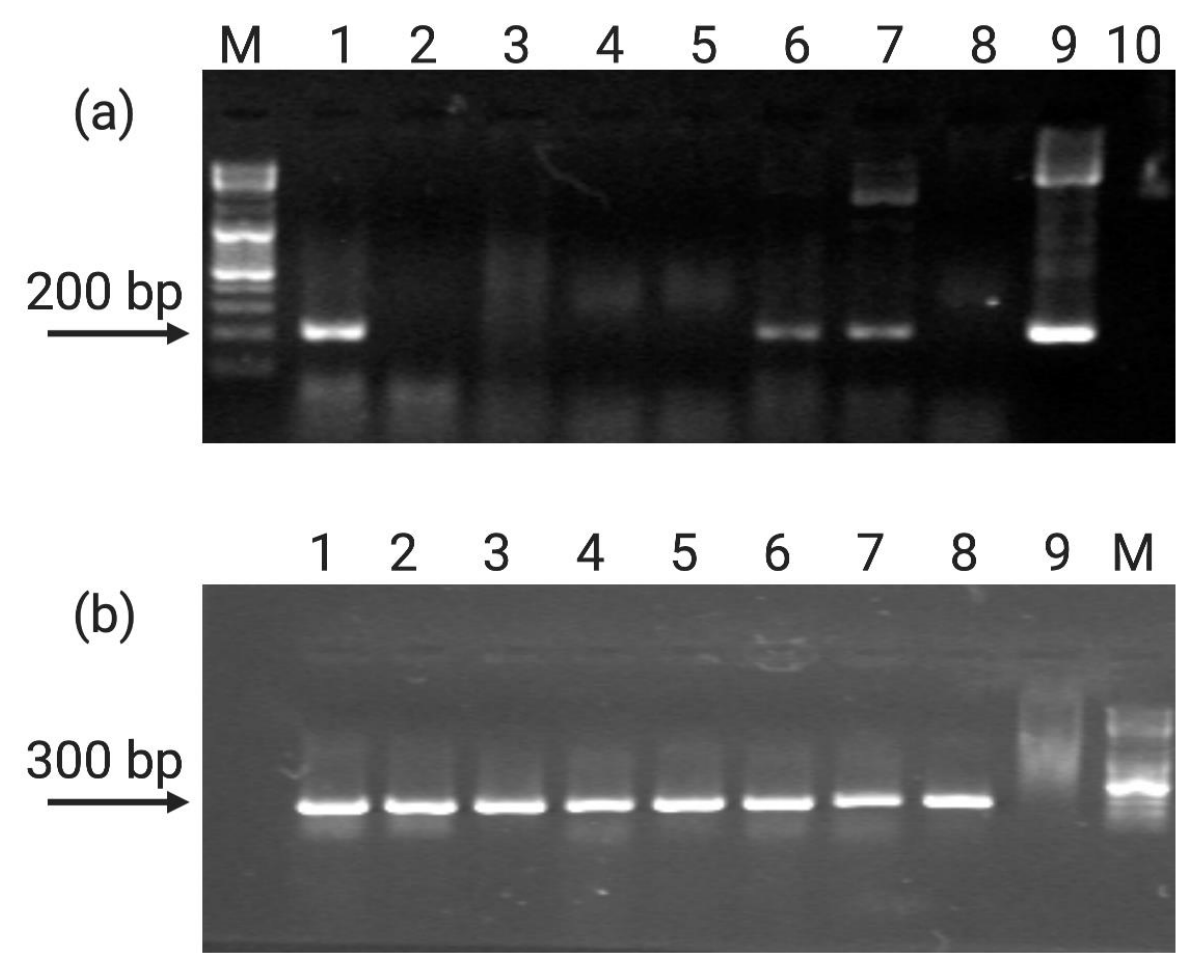

Figure 4. Electrophoretic profile showing the presence of GUS amplified fragment (215 bp) (a) and the housekeeping chloroplastic gene $(\mathbf{b})$ in transformed $A$. oleracea shoots. (a)M: Gene Ruler DNA ladder mix (Thermo Scientific); 1-7: A. oleracea transformants; 8: A. oleracea wild type control; 9: plasmid DNA as positive control; 10: PCR negative control. (b) 1-7: A. oleracea transformants; 8: A. oleracea wild type control; 9: PCR negative control; M: Gene Ruler DNA ladder mix.

After four months of culture under selection pressure, three GUS positive genotypes (pBI121 1, 6, and 7 transgenic lines) showed an in vitro growth as the wild type ones. Interestingly, in vitro flowering occurred in one of these genotypes (Figure 3h). They were then successfully grown in presence of increasing concentrations of kanamycin, namely the inhibitory doses 25, 50, and $100 \mathrm{mg} / \mathrm{L}$, and further analyzed for GUS expression. Figure S2 shows individual plants from each transgenic line subcultured on half strength LS medium supplemented with $100 \mathrm{mg} / \mathrm{L}$ kanamycin.

As evidenced from the dose-response curve (Section 2.2.1), the use of $25 \mathrm{mg} / \mathrm{L}$ kanamycin resulted extremely toxic during shoot differentiation. Remarkably, after genetic transformation, the putative transgenic regenerants were also able to grow on higher levels of kanamycin up to $100 \mathrm{mg} / \mathrm{L}$, confirming the efficacy of the reported method.

\subsubsection{GUS Gene Expression Analysis}

GUS transcription was demonstrated in the 4-month-old selected transgenic plants by RT-PCR. The presence of genomic DNA contamination in the same RNA samples had been ruled out by amplification of the CaMV promoter region. No amplification was detected in the untransformed control, transgenic samples, and negative control (RT-PCR reaction lacking RNA). Amplification only resulted for pBI121 plasmid DNA used as positive control (Figure 5A). The amplification with GusFw and GusRev primers produced the expected 215 bp long fragment (Figure 5B). 


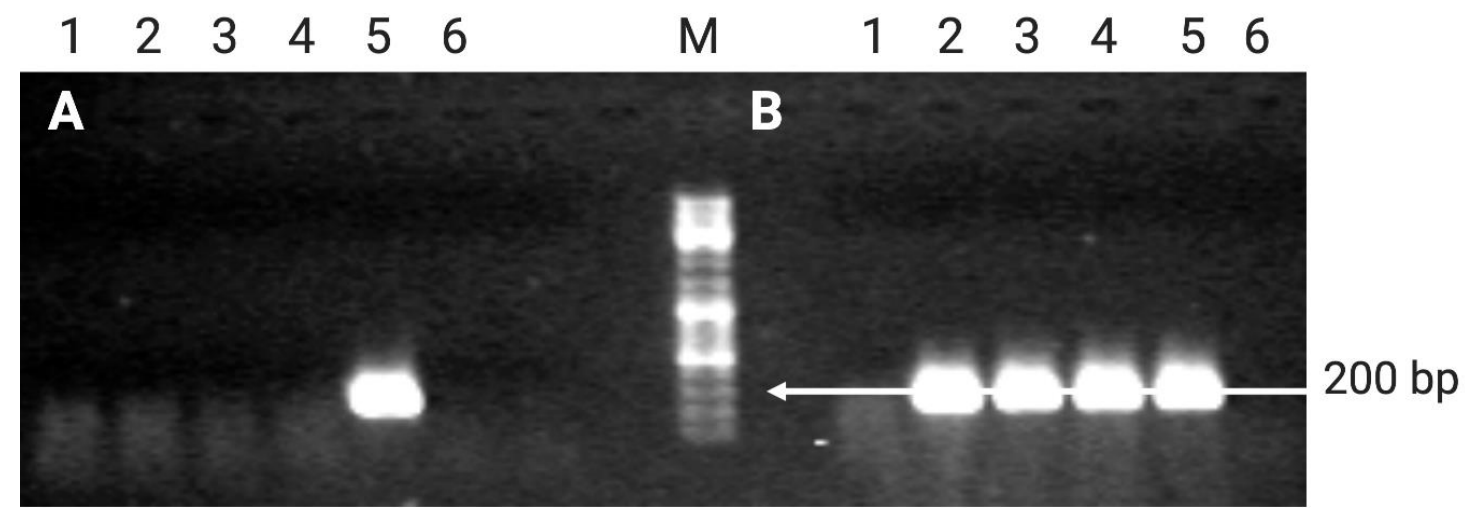

Figure 5. RT-PCR amplification on total RNA of (A) CaMV promoter and (B) GUS gene sequence from transformed and untransformed A. oleracea regenerated plants. 1: A. oleracea untransformed control; 2: A. oleracea pBI121_1 transgenic line; 3: A. oleracea pBI121_6 transgenic line; 4: A. oleracea pBI121_7 transgenic line; 5: positive control (pBI121 plasmid DNAl); 6: negative control (RT-PCR reaction without RNA); M: Gene Ruler DNA ladder mix (Thermo Scientific).

RNA quality was checked by the RT-PCR amplification of the chloroplastic PSBA housekeeping gene (Figure S3). The amplification was carried out with the primers pair psbAFW and psbAREV (Table S1) designed on the sequence of the Nicotiana tabacum gene [43] and produced the expected $942 \mathrm{bp}$ fragment in all samples. Coherently, in vivo GUS assay showed the characteristic blue color of the X-Gluc reaction in all transgenic lines tissues, indicating high GUS activity (Figure 6).

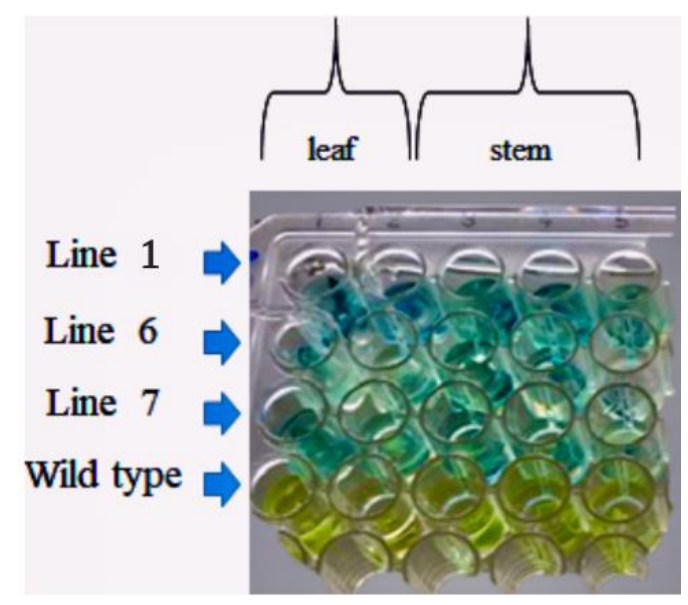

Figure 6. In vivo GUS assay on leaf and stem explants of A. oleracea transgenic and wild type regenerated plants.

\section{Materials and Methods}

\subsection{Plant Material and In Vitro Culture Establishment}

In vitro seedlings of A. oleracea were obtained from seeds (Saflax-Frank Laue, Münster, Germany); surface was sterilized using 5\% (v/v) hypochlorite containing a drop of Tween 20 and washed three times for $10 \mathrm{~min}$ in sterile distilled water. Surface-sterile seeds were then germinated on LS medium [44] containing $30 \mathrm{~g} / \mathrm{L}$ of sucrose (Lab Associates B.V., Oudenbosch, The Netherlands) and $0.7 \%$ of Phyto agar (Duchefa, Amsterdam, The Netherlands), and further grown in a growth chamber at $24 \pm 1{ }^{\circ} \mathrm{C}$ under a $16 \mathrm{~h}$ light $/ 8 \mathrm{~h}$ dark lighting condition. Acmella shoots were maintained in vitro by sub-culturing the upper part of the shoots on fresh LS medium at 20 days-intervals. 


\subsection{Regeneration by Organogenesis of A. oleracea}

For shoot regeneration, axenic leaf and stem nodal explants $0.7-1.5 \mathrm{~cm}$ in size were cultivated on LS medium supplemented with $1 \mathrm{mg} / \mathrm{L}$ 6-Benzylaminopurine (BAP, SigmaAldrich, Dordrecht, The Netherlands) and $0.1 \mathrm{mg} / \mathrm{L}$ 1-Naphthaleneacetic acid (NAA, Sigma-Aldrich, Dordrecht, The Netherlands) (LS1 medium) at $24 \pm 1^{\circ} \mathrm{C}$ under a $16 \mathrm{~h}$ light $/ 8 \mathrm{~h}$ dark lighting condition until shoot formation. For shoot elongation and root induction, each shoot $0.5 \mathrm{~cm}$ high was transferred on half strength LS medium without hormones and containing 2\% sucrose. Each regeneration experiment consisted of 20 explants and was repeated three times.

\subsection{Agrobacterium-Mediated Transformation of A. oleracea}

\subsubsection{Determination of Kanamycin Concentration for the Selection of Transformants}

To identify the optimal dose of kanamycin for the selection of putative transformants, the toxic effect of the antibiotic was verified at increasing concentrations from 5 to 10, 15, 25,50 , and $100 \mathrm{mg} / \mathrm{L}$. To this aim, five leaf and five nodal explants per dose were prepared and sown on LS1 medium with kanamycin as described. The experiment was repeated five times, for a total of 25 explants for each dose. For the preparation of leaf explants, a sterile $7 \mathrm{~mm}$ diameter cork borer was used; $1.5 \mathrm{~cm}$ nodal explants were obtained by cutting the stems with a sterile scalpel. After 4 weeks of culture in a growth chamber at $24 \pm 1{ }^{\circ} \mathrm{C}$, the explant differentiation capability was recorded.

\subsubsection{Leaf Disc Transformation and Molecular Analysis of Transformants}

Agrobacterium tumefaciens strain LBA4404 [45] containing the binary vector pBI121 [46] was used to transform the nodal explants of $A$. oleracea $\mathrm{L}$. with the leaf disc infection technique [47]. A single colony of the Agrobacterium strain was inoculated in $3 \mathrm{~mL}$ of liquid YEB medium supplemented with $50 \mathrm{mg} / \mathrm{L}$ kanamycin (selecting for the pBI121 vector) and $20 \mathrm{mg} / \mathrm{L}$ rifampicin (selecting for LBA4404 Agrobacterium strain), and grown in agitation at $28{ }^{\circ} \mathrm{C}$, overnight. One $\mathrm{ml}$ of the overnight suspension culture was then inoculated in $100 \mathrm{~mL}$ of fresh YEB medium, in presence of antibiotics and $100 \mu \mathrm{M}$ acetosyringone (Sigma-Aldrich, Dordrecht, The Netherlands), and kept at $28^{\circ} \mathrm{C}$ until $\mathrm{OD}_{600}=1$. Bacterial cells were then centrifuged at 10,000 rpm for $1 \mathrm{~min}$ and re-suspended in the same volume of LS basal medium. A 1:10 $(v / v)$ dilution of the bacterial suspension in LS medium was then used for co-cultivation. Nodal explants were dipped into the co-cultivation medium for $40 \mathrm{~min}$, blotted on sterile filter paper and then placed on Petri dishes (ten per dish) containing LS1 medium with $10 \mathrm{mg} / \mathrm{L}$ kanamycin as selection dose. Plates were maintained in the dark at $24 \pm 1{ }^{\circ} \mathrm{C}$ for $96 \mathrm{~h}$ for co-cultivation. For transgenic shoot regeneration, the explants were transferred on LS1 containing $10 \mathrm{mg} / \mathrm{L}$ kanamycin and $500 \mathrm{mg} / \mathrm{L}$ cefotaxime under a 16-h light photoperiod. Primary transformants were isolated after five weeks of culture and placed on a hormone-free selection medium containing $10 \mathrm{mg} / \mathrm{L}$ kanamycin and decreasing concentrations of cefotaxime (from 500 to $300 \mathrm{mg} / \mathrm{L}$ ) until the complete Agrobacterium elimination. Two independent experiments were carried out leading to the transformation of 30 nodal explants.

Before carrying out the molecular analysis by direct PCR, a sterility test was made to exclude the possibility that Agrobacterium was still present inside the intercellular spaces of putative transformed shoots. The sterility test is based on the absence of Agrobacterium growth in $3 \mathrm{~mL}$ of YEP medium supplemented with $20 \mathrm{mg} / \mathrm{L}$ rifampicin, $50 \mathrm{mg} / \mathrm{L}$ kanamycin, and $100 \mathrm{~mL}$ of leaf macerate obtained from each regenerated plant. To obtain the leaf macerate, an apical and a basal leaf from each individual shoot were crushed in $500 \mu \mathrm{L}$ of $0.9 \% \mathrm{NaCl}$ saline solution with a sterile pestle inside a sterile Eppendorf tube. The obtained macerates were then briefly centrifuged at $3000 \mathrm{rpm}$ to remove the leaf debris. One hundred $\mu . \mathrm{L}$ of supernatant were then inoculated in YEP medium containing the antibiotics. As positive control, $100 \mu \mathrm{L}$ of a $0.1 \mathrm{OD}_{600}$ Agrobacterium suspension culture were inoculated in the same culture medium. The solutions were incubated at $28^{\circ} \mathrm{C}$ in agitation and in the dark for $72-96 \mathrm{~h}$ and observed for the eventual bacterial growth. 
Transformation was confirmed using the Phire Plant Direct PCR Kit (Thermo Fisher Scientific $^{\mathrm{TM}}$, Waltham, MA, USA) in combination with a pair of primers (Table S1) able to amplify a region of the GUS gene present on the pBI121 T-DNA (GenBank accession number AF485783.1). Moreover, the universal primer mix provided by the kit was used to amplify a chloroplastic region $298 \mathrm{bp}$ long as positive control. The calculated annealing temperature for all primer pairs was $62{ }^{\circ} \mathrm{C}$, according to the manufacturer's instructions.

\subsubsection{GUS Assay with X-Gluc and GUS Expression Analysis with RT-PCR}

For GUS assay, stem and leaf samples from each isolated putative transgenic shoot were collected and dipped for fifteen min in $500 \mu \mathrm{L}$ of $100 \mathrm{mM}$ phosphate buffer $\mathrm{pH}$ 7.2, containing $1 \mathrm{mM}$ X-Gluc (5-bromo-4-chloro-3-indolyl- $\beta$-D-glucuronic acid) in N-Ndimethylformamide. Then, buffered X-Gluc was changed once and the samples were kept in an incubator at $37^{\circ} \mathrm{C}$ until color development. Samples were washed twice with $95 \%$ ethanol to bleach and better observe the color development.

To assess the expression of the GUS gene in Acmella GUS (+) transgenic lines, total RNA of three selected genotypes and wild type not transformed plantlets was extracted from the leaves following the instructions of the GeneJet Plant RNA purification mini kit (Life Technologies, Monza, Italy). DNA contamination was removed with the Thermo Scientific RapidOut DNA Removal kit (Life Technologies, Monza, Italy). RNA concentration was estimated by fluorometry using the Qubit quantitation platform by Invitrogen. RTPCR for the analysis of transgene expression was performed with the OneStep RT-PCR Kit (Qiagen, Venlo, The Netherlands) following the manufacturer's guidelines. RT-PCR amplification of the GUS transgene was performed on total RNA using GusFw and GusRev primers (Table S1).

\subsection{Statistical Data Analysis}

The analysis of variance between kanamycin treatments was performed using Oneway ANOVA $(p<0.05)$. For each experiment, 25 explants were sown (five explants per treatment, five replicates per treatment), and the experiment was repeated three times. Mean separations were performed using the method of Tukey. For the analysis, the PAST program version 1.89 was used [48].

\section{Conclusions}

In this work, we established a fast and efficient protocol for the genetic transformation of the emergent medicinal plant Acmella oleracea. The choice of nodal explants as source for the infection with Agrobacterium LBA4404::pBI121 and the use of $10 \mathrm{mg} / \mathrm{L}$ of kanamycin as selection agent were proven effective. Despite the presence of escape, the initially low antibiotic dose has successfully permitted both the selection and the regeneration of transformants, as confirmed by molecular techniques: real genetically transformed plantlets have then been stabilized under high selection pressure conditions. Moreover, the efficiency of transformation could be reduced by the presence of a mutation in the NPTII gene of pBI121 binary vector [46]; thus, other vectors with no mutations can be tested in order to increase the transformation efficiency in A. oleracea. Finally, a large number of nodal explants will allow obtaining a high number of recombinant shoots in only three months.

To our knowledge, this is the first report on the genetic transformation of A. oleracea. It could be performed with specific candidate genes for the production or the identification of novel bioactive compounds [31,32].

Supplementary Materials: The following are available online at https:/ / www.mdpi.com/2223-774 7/10/2/198/s1, Figure S1: Sterility test on Acmella transgenic shoots after 40 days from isolation and cultivation on LS selection medium with $10 \mathrm{mg} / \mathrm{L}$ kanamycin. 1-2: YEP medium with $100 \mathrm{~mL}$ of leaf macerates from two transgenic shoots, as an example; 3: YEP medium with $100 \mathrm{~mL}$ of leaf macerates from untransformed shoots; 4: YEP medium with $100 \mathrm{~mL}$ of saline solution (negative control); 5: YEP medium inoculated with LBA4404::pBI121 vector (positive control); Figure S2: Individual transgenic 
lines grown on half strength LS medium supplemented with $100 \mathrm{mg} / \mathrm{L}$ kanamycin; Figure S3: RTPCR amplification of the PSBA chloroplastic gene on total RNA from wild type (untransformed) and transformed with pBI121 binary vector A. oleracea plants; Table S1: List of primer pairs used for Phire PCR and RT-PCR experiments.

Author Contributions: Conceptualization, V.M. and P.B. (Patrizia Bogani); data curation, V.M. and P.B. (Patrizia Bogani); funding acquisition, F.F. and P.B. (Patrizia Bogani); investigation, V.M., P.B. (Priscilla Bettini) and P.B. (Patrizia Bogani); methodology, V.M., P.B. (Priscilla Bettini) and P.B. (Patrizia Bogani); project administration, F.F. and P.B. (Patrizia Bogani); supervision, F.F. and P.B. (Patrizia Bogani); writing-original draft, V.M. and P.B. (Patrizia Bogani); writing-review and editing, V.M. and P.B. (Priscilla Bettini). All authors have read and agreed to the published version of the manuscript.

Funding: This research was funded by Regione Toscana within Project "SENSOGM" (FAR FAS 2014 Line 1.1.5 a3) and Project "Medicine Complementari" (Resolution n. 1224/2016).

Institutional Review Board Statement: Not applicable.

Informed Consent Statement: Not applicable.

Data Availability Statement: All data reported here is available from the authors upon request.

Conflicts of Interest: The authors declare no conflict of interest. The funders had no role in the design of the study; in the collection, analyses, or interpretation of data; in the writing of the manuscript, or in the decision to publish the results.

\section{References}

1. Jansen, R.K. The Systematics of Acmella (Asteraceae-Heliantheae). Syst. Bot. Monogr. 1985, 8, 1. [CrossRef]

2. Singh, M.; Chaturvedi, R. Screening and quantification of an antiseptic alkylamide, spilanthol from in vitro cell and tissue cultures of Spilanthes acmella Murr. Ind. Crops Prod. 2012, 36, 321-328. [CrossRef]

3. Singh, M.; Chaturvedi, R. Evaluation of nutrient uptake and physical parameters on cell biomass growth and production of spilanthol in suspension cultures of Spilanthes acmella Murr. Bioprocess Biosyst. Eng. 2012, 35, 943-951. [CrossRef] [PubMed]

4. Abeysiri, G.R.P.I.; Dharmadasa, R.M.; Abeysinghe, D.C.; Samarasinghe, K. Screening of phytochemical, physico-chemical and bioactivity of different parts of Acmella oleraceae Murr. (Asteraceae), a natural remedy for toothache. Ind. Crops Prod. 2013, 50, 852-856. [CrossRef]

5. Martins, C.P.S.; Melo, M.T.P.; Honório, I.C.G.; D’Ávila, V.A.; Carvalho, W.G. Caracterização morfológica e agronômica de acessos de jambu (Spilanthes oleracea L.) nas condições do Norte de Minas Gerais. Rev. Bras. Plantas Med. 2012, 14, 410-413. [CrossRef]

6. Tiwari, K.L.; Jadhav, S.K.; Joshi, V. An updated review on medicinal herb genus Spilanthes. J. Chin. Integr. Med. 2011, 9, 1170-1178. [CrossRef]

7. Paulraj, J.; Govindarajan, R.; Palpu, P. The genus Spilanthes ethnopharmacology, phytochemistry, and pharmacological properties: A review. Adv. Pharmacol. Sci. 2013, 2013, 510298.

8. Prachayasittikul, V.; Prachayasittikul, S.; Ruchirawat, S.; Prachayasittikul, V. High therapeutic potential of Spilanthes acmella: A review. EXCLI J. 2013, 12, 291-312.

9. Lalchhandama, K.; Lalthanpuii, P.B.; Zokimi, Z. The toothache plant (Acmella oleracea) exhibits anthelmintic activity on both parasitic tapeworms and roundworms. Pharmacog. Mag. 2020, 16, 193. [CrossRef]

10. Uthpala, T.G.G.; Navaratne, S.B. Acmella oleracea plant; Identification, Applications and Use as an Emerging Food Source-Review. Food Rev. Int. 2020, 1-16. [CrossRef]

11. Lalthanpuii, P.B.; Lalchhandama, K. Chemical composition and broad-spectrum anthelmintic activity of a cultivar of toothache plant, Acmella oleracea, from Mizoram, India. Pharm. Biol. 2020, 58, 393-399. [CrossRef] [PubMed]

12. Dallazen, J.L.; Maria-Ferreira, D.; da Luz, B.B.; Nascimento, A.M.; Cipriani, T.R.; de Souza, L.M.; Felipe, L.P.G.; Silva, B.J.G.; Nassini, R.; de Paula Werner, M.F. Pharmacological potential of alkylamides from Acmella oleracea flowers and synthetic isobutylalkyl amide to treat inflammatory pain. Inflammopharmacology 2020, 28, 175-186. [CrossRef] [PubMed]

13. Lalthanpuii, P.B.; Lalchhandama, K. Intestinal cestodes of chicken are effectively killed by quinoline-rich extract of Spilanthes acmella. Vet. World 2020, 13, 821-826. [CrossRef] [PubMed]

14. Dallazen, J.L.; Maria-Ferreira, D.; da Luz, B.B.; Nascimento, A.M.; Cipriani, T.R.; de Souza, L.M.; Glugoski, L.P.; Silva, B.J.G.; Geppetti, P.; de Paula Werner, M.F. Distinct mechanisms underlying local antinociceptive and pronociceptive effects of natural alkylamides from Acmella oleracea compared to synthetic isobutylalkyl amide. Fitoterapia 2018, 131, 225-235. [CrossRef]

15. Dias, A.M.A.; Santos, P.; Seabra, I.J.; Júnior, R.N.C.; Braga, M.E.M.; de Sousa, H.C. Spilanthol from Spilanthes acmella flowers, leaves and stems obtained by selective supercritical carbon dioxide extraction. J. Supercrit. Fluids 2012, 61, 62-70. [CrossRef]

16. Simas, N.K.; da Costa Lima Dellamora, E.; Schripsema, J.; Lage, C.L.S.; de Oliveira Filho, A.M.; Wessjohann, L.; Porzel, A.; Kuster, R.M. Acetylenic 2-phenylethylamides and new isobutylamides from Acmella oleracea (L.) R. K. Jansen, a Brazilian spice with larvicidal activity on Aedes aegypti. Phytochem. Lett. 2013, 6, 67-72. [CrossRef] 
17. Dubey, S.; Maity, S.; Singh, M.; Saraf, S.A.; Saha, S. Phytochemistry, pharmacology and toxicology of Spilanthes acmella: A Review. Adv. Pharmacol. Sci. 2013, 2013, 423750.

18. Joshi, V.; Sharma, G.D.; Jadhav, S.K. Alkamides: Multifunctional bioactive agents in Spilanthes spp. J. Sci. Res. 2020, 64, 198-206. [CrossRef]

19. Barbosa, A.F.; de Carvalho, M.G.; Smith, R.E.; Sabaa-Srur, A.U.O. Spilanthol: Occurrence, extraction, chemistry and biological activities. Rev. Bras. Farmacogn. 2016, 26, 128-133. [CrossRef]

20. Nascimento, L.E.S.; Arriola, N.D.A.; da Silva, L.A.L.; Faqueti, L.G.; Sandjo, L.P.; de Araújo, C.E.S.; Biavatti, M.W.; BarcelosOliveira, J.L.; de Mello Castanho Amboni, R.D. Phytochemical profile of different anatomical parts of jambu (Acmella oleracea (L.) R.K. Jansen): A comparison between hydroponic and conventional cultivation using PCA and cluster analysis. Food Chem. 2020, 332, 127393. [CrossRef]

21. Sut, S.; Ferrarese, I.; Shrestha, S.S.; Kumar, G.; Slaviero, A.; Sello, S.; Altissimo, A.; Pagni, L.; Gattesco, F.; Dall'Acqua, S. Comparison of biostimulant treatments in Acmella oleracea cultivation for alkylamides production. Plants 2020, 9, 818. [CrossRef] [PubMed]

22. Rios-Chavez, P.; Ramirez-Chavez, E.; Armenta-Salinas, C.; Molina-Torres, J. Acmella radicans var. radicans: In vitro culture establishment and alkamide content. In Vitro Cell. Dev. Biol. Plant 2003, 39, 37-41. [CrossRef]

23. Saritha, K.V.; Naidu, C.V. Direct shoot regeneration from leaf explants of Spilanthes acmella. Biol. Plant. 2008, 52, 334-338. [CrossRef]

24. Deka, P.; Kalita, M.C. In vitro Clonal propagation and organogenesis in Spilanthes acmella (L) Murray: A herbal pesticidal plant of North-East India. J. Plant Biochem. Biotech. 2005, 14, 69-71. [CrossRef]

25. Pandey, V.; Agrawal, V. Efficient micropropagation protocol of Spilanthes acmella L. possessing strong antimalarial activity. In Vitro Cell. Dev. Biol. Plant 2009, 45, 491-499. [CrossRef]

26. Lima, N.K.; Da Silva, E.S.; Da Cruz, R.M.S.; Monteiro, P.H.R.; Da Silva, G.J. Plant growth regulators in the in vitro cultivation of Acmella oleracea (L.). J. Agric. Stud. 2020, 8, 774. [CrossRef]

27. Almeida, S.P.; Souza, J.M.M.; Amorim, A.M.T.; de Gusmão, S.A.L.; Souza, R.O.; Santos, A.S. In vitro culture of jambu with different growth regulators. Hortic. Bras. 2020, 38, 134-138. [CrossRef]

28. Singh, R.S.; Chattopadhyay, T.; Thakur, D.; Kumar, N.; Kumar, T.; Singh, P.K. Hairy root culture for in vitro production of secondary metabolites: A promising biotechnological approach. In Biotechnological Approaches for Medicinal and Aromatic Plants. Conservation, Genetic Improvement and Utilization; Kumar, N., Ed.; Springer: Singapore, 2018; pp. 235-250.

29. Li, C.; Wang, M. Application of hairy root culture for bioactive compounds production in medicinal plants. Curr. Pharm. Biotechnol. 2020. [CrossRef]

30. Shi, T.; Shi, J.; Xia, Z.; Lu, B.; Shi, S.; Fu, G. Precise control of variable-height laser metal deposition using a height memory strategy. J. Manuf. Processes 2020, 57, 222-232. [CrossRef]

31. Wilson, S.A.; Roberts, S.C. Metabolic engineering approaches for production of biochemicals in food and medicinal plants. Curr Opin. Biotechnol. 2014, 26, 174-182. [CrossRef]

32. Alok, A.; Jain, P.; Kumar, J.; Yajnik, K.; Bhalothia, P. Genome engineering in medicinally important plants using CRISPR/Cas9 tool. In Genome Engineering via CRISPR-Cas9 System, 1st ed.; Singh, V., Dhar, P.K., Eds.; Academic Press: Cambridge, MA, USA, 2020; pp. 155-161.

33. Khan, S.; Rahman, L.u. Pathway Modulation of medicinal and aromatic plants through metabolic engineering using Agrobacterium tumefaciens. In Transgenesis and Secondary Metabolism; Reference Series in Phytochemistry; Jha, S., Ed.; Springer: Cham, Switzerland, 2016; pp. 1-32.

34. Niazian, M. Application of genetics and biotechnology for improving medicinal plants. Planta 2019, 249, 953-973. [CrossRef] [PubMed]

35. Saritha, K.V.; Prakash, E.; Ramamurthy, N.; Naidu, C.V. Micropropagation of Spilanthes acmella Murr. Biol. Plant. 2002, 45, 581-584. [CrossRef]

36. Singh, M.; Chaturvedi, R. Optimization of Sphilanthes acmella L. cultivation by in vitro nodal segment culture. Acta Hortic. 2010, 109-114. [CrossRef]

37. Singh, S.K.; Rai, M.K.; Asthana, P.; Pandey, S.; Jaiswal, V.S.; Jaiswal, U. Plant regeneration from alginate-encapsulated shoot tips of Spilanthes acmella (L.) Murr., a medicinally important and herbal pesticidal plant species. Acta Physiol. Plant. 2009, 31, 649-653. [CrossRef]

38. Singh, S.K.; Rai, M.K.; Asthana, P.; Sahoo, L. An improved micropropagation of Spilanthes acmella L. through transverse thin cell layer culture. Acta Physiol. Plant. 2009, 31, 693-698. [CrossRef]

39. Matzk, A.; Mantell, S.; Schiemann, J. Localization of persisting agrobacteria in transgenic tobacco plants. MPMI-Mol. Plant Microbe Interact. 1996, 9, 373-381. [CrossRef]

40. Praveen, M.; Nanna, R.S. Influence of antibiotics on regeneration efficiency in tomato. Plant Omics 2009, 2, 135.

41. Retheesh, S.T.; Bhat, A.I. Genetic transformation and regeneration of transgenic plants from protocorm-like bodies of vanilla (Vanilla planifolia Andrews) using Agrobacterium tumefaciens. J. Plant Biochem. Biotechnol. 2011, 20, 262. [CrossRef]

42. Priya, A.M.; Pandian, S.K.; Manikandan, R. The effect of different antibiotics on the elimination of Agrobacterium and high frequency Agrobacterium-mediated transformation of indica rice (Oryza sativa L.). Czech J. Genet. Plant Breed. 2012, 48, 120-130. [CrossRef] 
43. Bettini, P.P.; Chiarugi, P.; Buiatti, M. An in vitro molecular study of the Nicotiana tabacum L. genome in the presence or absence of the herbicide atrazine. Theor. Appl. Genet. 1998, 96, 242-250. [CrossRef]

44. Linsmaier, E.M.; Skoog, F. Organic Growth Factor Requirements of tobacco tissue cultures. Physiol. Plant. 1965, 18, 100-127. [CrossRef]

45. Ooms, G.; Hooykaas, P.J.; Van Veen, R.J.; Van Beelen, P.; Regensburg-Tuïnk, T.J.; Schilperoort, R.A. Octopine Ti-plasmid deletion mutants of Agrobacterium tumefaciens with emphasis on the right side of the T-region. Plasmid 1982, 7, 15-29. [CrossRef]

46. Chen, P.Y.; Chen-Kuen, W.; Shaw-Ching, S.; Kin-Ying, T. Complete sequence of the binary vector pBI121 and its application in cloning T-DNA insertion from transgenic plants. Mol. Breed. 2003, 11, 287-293. [CrossRef]

47. Horsch, R.B.; Fry, J.E.; Hoffmann, N.L.; Eichholtz, D.; Rogers, S.G.; Fraley, R.T. A simple and general method for transferring genes into plants. Science 1985, 227, 1229-1231.

48. Hammer, Ø.; Harper, D.A.T.; Ryan, P.D. PAST-PAlaeontological STatistics, ver. 1.89. Palaeontol. Electron. 2009, 4, 1-9. 